\title{
Effects of Some Coronary "Vasodilators" on Myocardial Catecholamine
}

\author{
Shingo Aoyama, M.D.*
}

The effects of the so-called "Vasodilators" on catecholamine concentrations of the normal and the infarcted area of the dog left ventricular muscle were studied. Myocardial infarction of the dog was produced by the ligation of the left coronary artery. Catecholamines measured were adrenaline, noradrenaline (T.H.I. method) and dopamine (E.D.C. method). Vasodilators used were theophylline ethylenediamine, Persantin, nitroglycerine, Segontin, Niamide and Nardil.

MAO inhibitors (Niamide and Nardil) increased the myocardial catecholamine concentrations. Noradrenaline concentration of the infarcted area was greater than that of normal area after the administration of MAO inhibitors. The administration of a large dose of Nardil caused a decrease in myocardial adrenaline concentration.

Segontin decreased the myocardil catecholamine concentration, especially noradrenaline concentrations of the infarcted area.

Nitroglycerine increased the myocardial concentration of noradrenaline and dopamine. The action of nitroglycerine on catecholamine metabolism discussed. Theophylline ethylendiamine, Persantin did not seem to affect profoundly on the myocardial catecholamine concentration.

$\mathrm{R}^{\mathrm{r}}$ ECENTLY knowledge of catecholamine metabolism has been developed and its physiological significance has been elucidated. ${ }^{1-4)}$ Many reports about the significance of catecholamine in myocardial infarction and angina pectoris have been published. The metabolism of catecholamine in the diseases might be different from the normal and it might play a great role in the pathophysiology of these diseases. ${ }^{51-81}$

* Professor of Internal Medicine, Second Department of Internal Medicine, Nagoya University School of Medicine, Nagoya

Presented in part before the 26th annual meeting of the Japanese Circulation Society, Tokyo, March 30th, 1962 and before the 14th Tokai regional meeting of the Japanese Circulation Society, Tsu, Mie Prefecture, June 30th, 1962.

Persantin $=[2.6-$ Bis $($ diethanolamino $)-4.8$-dipiperidinopyrimido $(5.4-\mathrm{d})$ pyrimidine $]$ was kindly supplied by C.H. Boehringer Sohn.

Segontin $=\left[N-\left[3^{\prime}-\right.\right.$ phenylpropyl- $\left.\left.\left\langle 2^{\prime}\right\rangle\right]\right]$, 1 - diphenylpropyl-(3)-Amin $]$ was kindly supplied by Japan Hoechst A.G.

Niamide $=$ Nialamide $=[1-[2-$ (benzylcarbamyl) - ethyl $]-2-$ iso nicotineylhydrazine $]$ was kindly supplied by Pfizer-'Taito Co.

Nardil $=$ phenelzine was kindly supplied by Ono Pharam. Co. 


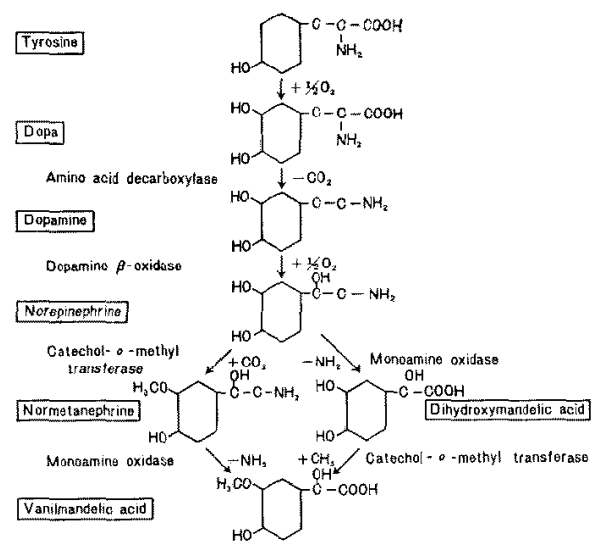

Fig. 1.

On the other hand, the reports indicating that some of the so-called "Vasodilators" affect directly catecholamine metabolism profoundly have been published. ${ }^{9), 10)}$

The present study describes the effects of "vasodilators" on the catecholamine concentrations of the normal and infarcted dog myocardium (Fig. 1).

\section{Material and Method}

Thirty-six mongrel dogs were used in all experiments. The animals were divided into 3 groups. One group was served for control and the others for experiments.

Acute myocardial infarction of the dog was produced by the ligation of the left coronary artery under the open chest surgery of pentobarbital anesthesia and artificial air inhalation. Thirty min. after the ligation of the left coronary artery, "vasodilators" were injected. Theophylline ethylenediamine, Persantin, Segontin, nitroglycerine, Niamide and Nardil were used. "Valodilators" were administered by the subcutaneous injections at the dose level of $50 \mathrm{mg} . / \mathrm{Kg}$. of theophylline ethylenediamine, $0.5 \mathrm{mg} . / \mathrm{Kg}$. of Persantin, $0.015 \mathrm{mg} . / \mathrm{Kg}$. of nitroglycerine, $2.0 \mathrm{mg} . / \mathrm{Kg}$. of Segontin, $3.0 \mathrm{mg} / \mathrm{Kg}$. of Niamide, $0.5 \mathrm{mg} . / \mathrm{Kg}$. and $1.5 \mathrm{mg} . / \mathrm{Kg}$. of Nardil respectively.

The normal and the infarcted areas of the left ventricular muscle were used for the measurement of catecholamine after $30 \mathrm{~min}$. of the administration of these drugs. The catecholamines measured were adrenaline, noradrenaline and dopamine.

Preparation of Tissue

After $30 \mathrm{~min}$. of administration of these drugs, dogs were bled. Quickly opening the chest, the beating heart was excised. The excised heart was immediately opened, blood was washed out with cold tap water and the heart was placed in the glass beaker surrounded by ice. After the pericardium, epicardial 
fat and base of the great vessels were removed by dissector, the muscle of the left ventricle of $\operatorname{dog}$ was weighed and minced fincly with scissors.

Each cardiac muscle normal and treated above mentioned was homogenized with 2 volumes of $10 \%$ TCA and $0.1 \%(\mathrm{w} / \mathrm{v})$ sodium ethylenediamine tetra acetate (pH. 7.0).

Separation of Catechol Franctions

The method of separation of catechol fractions was followed by that of WeilMalherbe and Bone. ${ }^{11)}$ And all procedures were carried out under the room temperature $10^{\circ} \mathrm{C}$. After standing $30 \mathrm{~min}$. the samples of homogenate were centrifuged at 4,000 R.P.M. and washed two times with $3 \mathrm{ml}$. of $10 \%$ TCA and $0.1 \%$ EDTA. Thirty minutes after adding to the precipitate $3 \mathrm{ml}$. of $10 \%$ TCA and $0.1 \%$ EDTA, the homogenates were centrifuged again and each supernatant solution was added to the supernatant previously prepared. One tenth vol. of $1 \%$ EDTA and 0.1 vol. of a freshly prepared $1 \%(\mathrm{w} / \mathrm{v})$ solution of ascorbic acid were added to the supernatant solutions. The $\mathrm{pH}$ of the solution was adjusted 8.4 and passed through alumina columns which was prepared by the method of WeilMalherbe, ${ }^{11)}$ and then brought to $\mathrm{pH} 6.5$ and passed over columns of damp Amberlite IRG-50 buffered at $\mathrm{pH} 6.5$. The columns were washed with $40 \mathrm{ml}$. of water and eluted with $10 \mathrm{ml}$. of $1 \mathrm{~N} \mathrm{HCl}$. The filtrates and washings were combined and set aside for further analysis (Fig. 2).

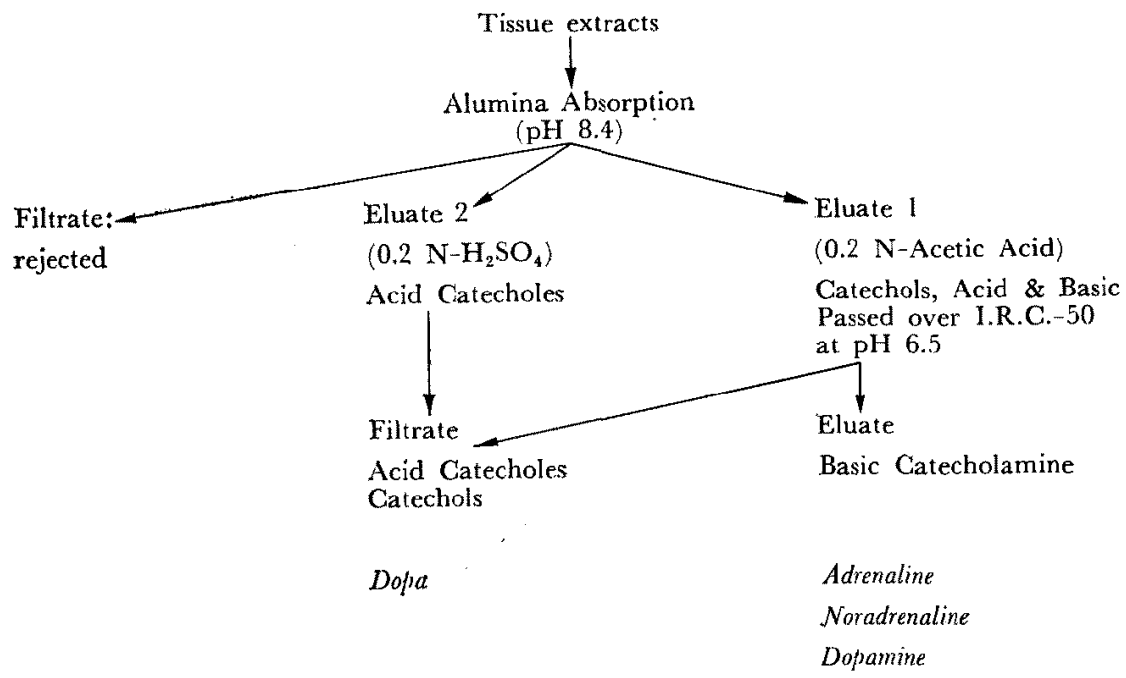

Fig. 2. Schema for chemical fractionation of tissue extracts.

Fluorimetric Analysis

Adrenaline and noradrenaline were determined by the trihydroxylindole method (T.H.I. method). The ethylenediamine condensation method was performed on another aliquot of the solution, yielding fluorescent derivatives of adrenaline, noradrenaline and dopamine. Dopamine concentration was calculated by subtracting the fluorescence of adrenaline and noradrenaline from the total fluorescence. Fluorimetric determination was carried on by a fluorophotometer designed by Yagi. Adrenaline and noradrenaline were differentiated by oxidation at pH 3.5 and 6.0 respectively, according to Euler and Floding. ${ }^{13)}$ By the 
addition of small amounts of ethylenediamine to the alkali-ascorbic acid mixture used in the T.I.H. method, the discoloration of reaction mixture and instability of fluorescence could be prevented. So the alkali-EDA-ascorbic acid mixture was used for the stabilization of the lutine ${ }^{14)}$ (Table I).

Table I. Fluorimetric Analysis

1) Adrenaline Noradrenaline - Trihydroxyindole Method (T.H.I. method)

3) Doparnine _- Ethylenediamine Condensation Method (E.D.C. method)

\section{Results}

The mean concentrations of adrenaline, noradrenaline and dopamine in the left ventricle of the 6 dog hearts were $0.047 \mu \mathrm{g} . / \mathrm{Gm} ., 0.93 \mu \mathrm{g} . / \mathrm{Gm}$. and $0.36 \mu \mathrm{g} . / \mathrm{Gm}$. respectively. The concentrations of those of the infarcted area were $0.06,0.72$ and $0.44 \mu \mathrm{g} . / \mathrm{Gm}$. respectively after $60 \mathrm{~min}$. of the ligation of the left coronary artery. The mean noradrenaline concentration was reduced from $0.93 \mu \mathrm{g} . / \mathrm{Gm}$. to $0.72 \mu \mathrm{g} . / \mathrm{Gm}$. Therefore, the loss was $20 \%$ after the ligation of the coronary artery (Table II) (Fig.3).

The Effects of Vasodilators on the Catecholamine Concentrations of the Normal Cardiac Muscle (Table III) (Fig. 4)

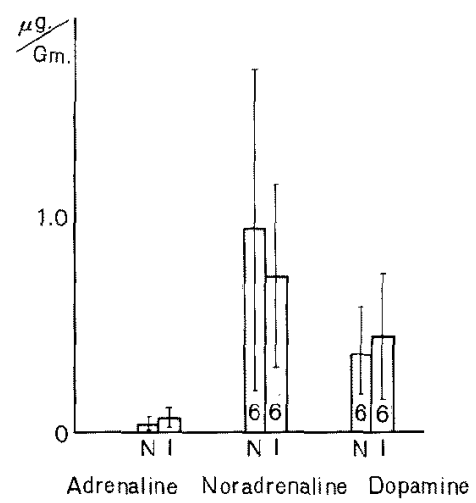

Fig. 3. Mean catecholamine concentrations of normal and infarcted area of the left ventricular muscle of 6 dogs.

$\mathrm{N}$ : Non-infarcted I : Infarcted

Table II. Mean Concentration of Catecholamines of Normal and Infarcted Area of the Left Ventricular Muscle of 6 Dogs $(\mu \mathrm{g} . / \mathrm{Gm} . \pm \mathrm{s} . \mathrm{d}$.)

\begin{tabular}{l|c|c|c}
\hline & Ndrenaline & Noradrenaline & Dopamine \\
\hline Normal & $0.0469 \pm 0.027$ & $0.927 \pm 0.837$ & $0.358 \pm 0.187$ \\
Infarcted & $0.0605 \pm 0.005$ & $0.717 \pm 0.478$ & $0.443 \pm 0.313$
\end{tabular}




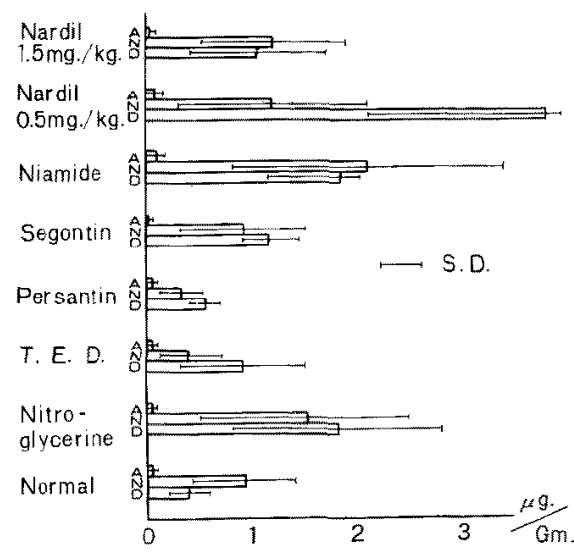

Fig. 4. Effects of " coronary vasodilators" on the catecholamine concentration of normal myocardium. A: Adrenaline $\mathrm{N}$ : Noradrenaline $\mathrm{D}$ : Dopamine

a) Theophylline Ethylenediamine

There were no alterations in the concentrations of adrenaline and noradrenaline after $60 \mathrm{~min}$. of theophylline ethylenediamine administration. But a slight increase in dopamine and a decrease in noradrenaline was observed (mean $0.92 \mu \mathrm{g} . / \mathrm{Gm}$. and $0.77 \mu \mathrm{g} . / \mathrm{Gm}$. respectively).

b) Pcrsantin

Persantin seemed to have a little effect on the myocardial concentrations of adrenaline. The concentration of dopamine was slightly increased from $0.36 \mu \mathrm{g} . / \mathrm{Gm}$. to $0.56 \mu \mathrm{g} . / \mathrm{Gm}$. without statistical significance, while noradrenaline decreased from $0.93 \mu \mathrm{g} . \mathrm{Gm}$. to $0.74 \mu \mathrm{g} . \mathrm{Gm}$.

c) Nitroglycerine

The administration of nitroglycerine increased noradrenaline and dopamine concentrations (mean $1.52 \mu \mathrm{g} . / \mathrm{Gm}$. and $1.83 \mu \mathrm{g} . \mathrm{Gm}$. respectively) after $30 \mathrm{~min}$. but this was not statistically significant comparing with those of the control.

d) Segontin

Segontin decreased the adrenaline concentration. On the contrary, an increase in dopamine concentration was observed.

e) Niamide

Niamide, which is a monoamine oxidase inhibitor, increased markedly adrenaline, noradrenaline, and dopamine concentrations (mean $0.091 \mu \mathrm{g} . / \mathrm{Gm}$. $2.17 \mu \mathrm{g} . / \mathrm{Gm}$. and $1.87 \mu \mathrm{g} / \mathrm{Gm}$. respectively).

f) Nardil (0.5 mg. $/ \mathrm{Kg}$.)

The same tendency as Niamide was observed especially in adrenaline and dopamine concentrations after the administration of a small dose of 
Table III. Mean Concentration of Catecholamines of Non-infarcted and Infarcted Area of the Left Ventricular Muscle of Dogs after the Administration of "Vasodilators" ( $\mu$ g./Gm. \pm s.d.)

\begin{tabular}{|c|c|c|c|c|c|c|}
\hline & Vasodiator & $\begin{array}{l}\text { No. of } \\
\text { Cases }\end{array}$ & Myocardium & Adrenaline & Noradrenaline & Dopamine \\
\hline \multirow[t]{2}{*}{ a) } & 'Theophylline & 4 & Non-infarcted & $0.052 \pm 0.038$ & $0.775 \pm 0.445$ & $0.921 \pm 0.791$ \\
\hline & ethylenediamine & & Infarcted & $0.053 \pm 0.089$ & $0.744 \pm 0.432$ & $0.724 \pm 0.445$ \\
\hline \multirow[t]{2}{*}{ b) } & Persantion & 4 & Non-infarcted & $0.060 \pm 0.077$ & $0.741 \pm 0.685$ & $0.561 \pm 0.149$ \\
\hline & & & Infarcted & $0.078 \pm 0.084$ & $0.754 \pm 0.279$ & $0.630 \pm 0.255$ \\
\hline \multirow[t]{2}{*}{ c) } & Nitroglycerine & 5 & Non-infarcted & $0.043 \pm 0.038$ & $1.520 \pm 1.12$ & $1.831 \pm 1.461$ \\
\hline & & & Infarcted & $0.048 \pm 0.050$ & $1.632 \pm 0.86$ & $2.069 \pm 1.71$ \\
\hline \multirow[t]{2}{*}{ d) } & Segontin & 5 & Non-infarcted & $0.019 \pm 0.029$ & $0.918 \pm 0.418$ & $1.173 \pm 0.253$ \\
\hline & & & Infarcted & $0.019 \pm 0.029$ & $0.391 \pm 0.300$ & $1.069 \pm 0.203$ \\
\hline e) & Niamide & 4 & Non-infarcted & $0.092 \pm 0.113$ & $2.171 \pm 1.342$ & $1.872 \pm 0.439$ \\
\hline \multirow[t]{3}{*}{ f) } & Nardil $(0.5 \mathrm{mg} . / \mathrm{Kg})$. & 4 & Infarcted & $0.045 \pm 0.019$ & $2.942 \pm 2.487$ & $1.474 \pm 1.008$ \\
\hline & & & Non-infarcted & $0.077 \pm 0.016$ & $1.195 \pm 1.023$ & $3.643 \pm 1.758$ \\
\hline & & & Infarcted & $0.089 \pm 0.003$ & $2.184 \pm 1.652$ & $1.742 \pm 1.260$ \\
\hline \multirow[t]{2}{*}{ g) } & Nardil (1.5 mg./Kg.) & 4 & Non-infarcted & $0.002 \pm 0.002$ & $1.199 \pm 1.066$ & $1.476 \pm 1.219$ \\
\hline & & & Infarcted & $0.004 \pm 0.005$ & $1.478 \pm 1.854$ & $0.889 \pm 0.262$ \\
\hline
\end{tabular}

Nardil $(0.5 \mathrm{mg} . \mathrm{Kg}$.$) with the level of significance less than 0.05$ (mean $0.077 \mu \mathrm{g} . / \mathrm{Gm}$. and $3.6 \mu \mathrm{g} . / \mathrm{Gm}$. respectively).

g) Nardil (1.5 mg./Kg.)

The administration of a large dose of Nardil $(1.5 \mathrm{mg} . / \mathrm{Kg}$.) caused a statistically significant decrease of adrenaline. This formed a sharp contrast to those of small dose of administration.

The Effects of Vasodilators on the Catecholamine Concentrations of the Infarcted Cardiac Muscle (Table III) (Fig. 5)

a) Theophylline Ethylenediamine

Theophylline ethylenediamine had no remarkable effects on the infarcted muscle compared with those on the non-infarcted muscle.

b) Persantin

The effect of Persantin on the catecholamine concentration of the infarcted myocardium was also negligible compared with that of the noninfarcted myocardium.

c) Nitroglycerine

Nitroglycerine increased the dopamine concentration of the infarcted myocardium compared with that of the non-infarcted myocardium but this increase was not statistically significant.

d) Segontin

The effect of Segontin on the noradrenaline concentration of the infarcted myocardium was remarkable (mean concentration of noradrenaline 

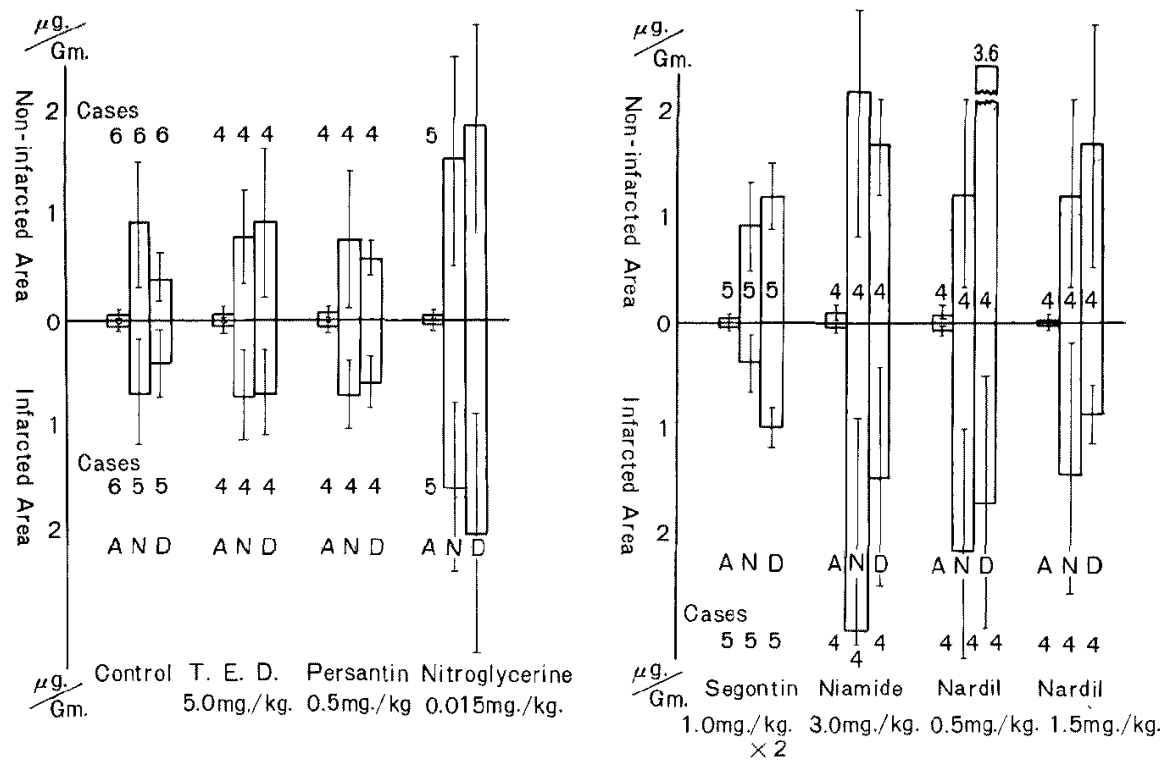

Fig. 5. Effects of "coronary vasodilators" on the catecholamine concentration of the non-infarcted and infarcted myocardium of dogs.

was $0.39 \mu \mathrm{g} . / \mathrm{Gm}$.). The decrease was statistically significant with $\mathrm{p}<0.05$ compared with the non-infarcted myocardium (mean $0.92 \mu \mathrm{g} . / \mathrm{Gm}$.).

e) Niamide

The effects of Niamide on the infarcted myocardium were a remarkable increase in noradrenaline and a decrease in dopamine compared with the non-infarcted myocardium.

f) Nardil (0.5 mg./Kg.)

The administration of a relatively small dose of Nardil $(0.5 \mathrm{mg} . / \mathrm{Kg}$.) caused a statistically significant increase in noradrenaline and a decrease in dopamine.

g) Nardil (1.5 mg./kg.)

The administration of a relatively large dose of Nardil $(1.5 \mathrm{mg} . / \mathrm{Kg}$. also caused an increase in noradrenaline and a decrease in dopamine in the infarcted myocardium.

\section{Discussion}

The quantities of catecholamine in the normal myocardium of the dog vary to some extent, depending on the method of analysis. Miyahara found using column chromatography and fluorimetric determination, $0.82 \mu \mathrm{g} . / \mathrm{Gm}$. of noradrenaline and $0.53 \mu \mathrm{g} . / \mathrm{Gm}$. of dopamine, and extensively low con- 
centration of adrenaline to be measured accurately. ${ }^{15}$ ) Klouda determined the distribution of catecholamines in the dog heart and found that noradrenaline content of the right auricle was $1.46 \mu \mathrm{g}$. $/ \mathrm{Gm}$., the left auricle $1.13 \mu \mathrm{g} . / \mathrm{Gm}$, the right ventricle $0.80 \mu \mathrm{g} . / \mathrm{Gm}$., the left ventricle $0.62 \mu \mathrm{g} . / \mathrm{Gm}$. and the septum $0.67 \mathrm{\mu g} . / \mathrm{Gm}{ }^{16)}$ Raab and Gigee, using a bioassay technique, found 0.14 $\mu \mathrm{g} . / \mathrm{Gm}$. of noradrenaline and $0.0017 \mu \mathrm{g} . / \mathrm{Gm}$. of adrenaline. ${ }^{17)}$ Russel et al. found considerably higher concentration of noradrenaline, $0.5-0.6 \mu \mathrm{g} . / \mathrm{Gm}$. in the apex and the distribution of adrenaline was uniform throughout the ventricle, ranging between 0.015 and $0.025 \mu \mathrm{g}$. $/ \mathrm{Gm}$. Euler's bio-assay in the cat heart yielded higher values for both amines than his determination in the dog. ${ }^{19)}$ Author's determination gave almost the same order of values as those of Miyahara. One hour after the coronary ligation, the mean noradrenaline concentration reduced from $0.93 \mu \mathrm{g}$. $/ \mathrm{Gm}$. to $0.73 \mu \mathrm{g}$. $/ \mathrm{Gm}$. and the loss was $20 \%$. Russel et al. found the same tendency from $0.8 \mu \mathrm{g} . / \mathrm{Gm}$. to 0.64 $\mu \mathrm{g} . / \mathrm{Gm}$. after 1 hour of coronary artery ligation. ${ }^{18)}$

Unghvary et al. found that the catecholamine content of blood decreased to 50 to $30 \%$ of normal after $5 \mathrm{~min}$. of the administration of Persantin. ${ }^{43)}$ According to the present study, theophylline ethylenediamine and Persantin had no significant effect on the catecholamine concentrations both of infarcted and non-infarcted myocardium.

On the other hand, MAO inhibitors such as Nardil and Niamide affected profoundly on the catecholamine concentration of the myocardium. Noradrenaline concentration of the infarcted myocardium was higher than that of the non-infarcted myocardium after the administration of MAO inhibitors. Trendelenburg has suggested that noradrenaline could be divided into 2 compartments, a "bound" form and an "available" form. ${ }^{20)}$ Using an isolated canine heart preparation, Braunwald et al.41,211 showed that the extraction of noradrenaline during a simple circulation through the coronary bed was large $(74 \%)$, and suggested 4 possible fates for the noradrenaline released from its intracellular storage sites as a result of nerve impulses or humoral stimuli:

1) the adrenergic neurotransmitter may attach to the receptor site of an effector organ, such as the heart, producing an adrenergic response,

2) it may undergo enzymatic degradation (MAO, COMT),

3) it may return to the store whence it came, or

4) it may overflow into blood.

Kopin and Gordon ${ }^{22}$ have shown that noradrenaline released by tyramine is metabolized primarily by catechol-o-methyl transferase, while noradrenaline released by reserpine serves as a substrate for deamination by monoamine oxidase. These works suggest that the increased noradrenaline in the in- 
farcted myocardium after MAO inhibitor may be the "available" form from the blood which was increased by MAO inhibitor administration. According to Pletscher, ${ }^{23)}$ it is suspected that property of MAO inhibitors includes deposition of noradrenaline in a bound, pharmacodynamically inactive form. There was a sharp contrast on the adrenaline concentration between the administration of large dose and small dose of Nardil. The difference of these 2 doses was very interesting. Goldberg and Shideman ${ }^{44}$ showed that iproniazid, monoamine oxidase inhibitor, increased the concentration of myocardial catecholamine in guinea pigs and rats. However, they observed that the administration of SKF 385 caused the depletion of myocardial catecholamine at least in one species of animals (cats and rats).

Segontin showed the tendency of adrenaline-depleting effect and these rcsults were supported by Shone and Lindner. ${ }^{10}$

The mechanism of action of nitroglycerine is less clearly established. ${ }^{24)}$ Classic theory attributes the action of nitroglycerine to coronary vasodilation and increased coronary blood flow. ${ }^{25-33)}$ Others believe coronary flow to be diminished or unchanged, and attribute relief of ischemia to reduced cardiac work and oxygen requirement. ${ }^{34)-38}$ By the coronary sinus catheterization technique, Gorlin and his associates ${ }^{38)}$ showed that the "fixed coronary flow" of patients with angina pectoris did not respond to nitroglycerine in contrast to the reaction of the coronary arteries in normal subjects. Raab and Lepeschkin ${ }^{45)}$ suggested that nitroglycerine strikingly counteracted the typical cardioaccelerating and T-wave depressing effects of adrenaline, noradrenaline, and neurally discharged or injected cardiac sympathine. This phenomenon was interpreted as being due to an interference of nitroglycerine with the metabolic, anoxia-producing effects of the sympathomimetic amines on the heart muscle rather than to the familiar coronary dilator action of nitroglycerine. Unghvary reported that nitrogylcerine decreased the blood catecholamine levels to $50 \sim 30 \%$ of the normal after $15 \sim 30 \mathrm{~min}$. of the administration and recovered to normal level after $60 \sim 80 \mathrm{~min}^{43}$ ) Glyceryl trinitrate strongly inhibits aortic ATPase activity in rats and decreases oxygen uptake by rabbit aortic homogenates. ${ }^{39)}$ Krantz has shown that therapeutic concentration of nitroglycerine was without effect on the $\mathrm{O}_{2}$ consumption of the uterine and skeletal muscle. ${ }^{40)}$ Using a modification of the Warburg technic, Honing et al. found that the oxygen uptake of the cardiac muscle also was unaffected, even during the first $5 \mathrm{~min}$. of exposure. ${ }^{41}$ Hunter et al. found that relatively low concentrations of mannitol hexanitrate inhibited electron transport.42) Glyceryl trinitrate was far less effective. Using mitochondria derived from the cardiac muscle, Honing et al. observed almost complete inhibition of phosphorylation at high concentration of nitro- 
glycerine, as well as slight but diffinite inhibition with concentrations that might be obtained in vivo. ${ }^{41)}$ These studies offer a biochemical mechanism for the apparent oxygen wasting. The present data showed that nitroglycerine increased noradrenaline and dopamine concentration. Its effects were similar to those of Niamide and Nardil, and its study presents an intriguing field for the research on angina pectoris. Further studies into this problem are necessary.

\section{SUmmary}

The effects of the so-called "Vasodilators" on adrenaline, noradrenaline and dopamine concentrations of the normal and the infarcted area of the dog left ventricular muscle were studied. Vasodilators used were theophylline ethylenediamine, Persantin, nitroglycerine, Segontin, Niamide and Nardil.

(1) Niamide and Nardil which are MAO inhibitors, increased the myocardial catecholamine concentrations. Noradrcnaline concentration of the infarcted area was greater than that of normal area after the administration of MAO inhibitors. However, the administration of a large dose of Nardil caused a decrease in myocardial adrenaline concentrations. This is a distinct contrast to the administration of a small dose of Nardil.

(2) Segontin decreased the myocardial catecholamine concentration, especially noradrenaline concentrations of the infarcted area. This decrease was a sharp contrast to the increase in noradrenaline concentration after the administration of Nardil.

(3) Nitroglycerine increased the myocardial concentration of noradrenaline and dopamine. However, the mechanism of nitroglycerine on the catecholamine metabolism remained to be investigated.

(4) Theophylline ethylenediamine, Persantin did not seem to affect profoundly on the myocardial catecholamine concentration.

\section{ACKNOWLEDGEMENT}

Cooperation of the following members of 2nd Department of Internal Medicine was much acknowledged.

Drs. H. Matsubara, T. Watanabe, N. Yamazaki, K. Ogawa, K. Mizutani, K. Taguchi, S. Kato, S. Kobayashi, and H. Aoyama.

\section{REFERENCES}

1. Euler, U.S. v. and Luft, R.: Brit. J. Pharmacol. 6 : 286, 1951.

2. Armstrong, M.D., McMillan, A., and Shaw, K.N.F.: Biochem. Biophys. Acta 25 : 422, 1957. 
3. Crout, J.R., Creveling, C.R., and Udenfriend, S. : J. Pharm. Exp. Therap. 132 : 269, 1961.

4. Braunwald, E., Chidsey, C.A., Harrison, D.C., Gaffrey, T.E., and Kaler, R.L. : Circulation, 28 : $958,1963$.

5. Levine, S.A., Ernstene, A.C., and Jacobson, B.H.: Arch. Int. Med. 45 : 191, 1930.

6. Raab, W.: Am. J. Cardiol. 5 : 571, 1960.

7. Raab, W.: Hormonal and Neurogenic Cardiovascular Disorders, Williams \& Wilkins Baltimore, 1953.

8. Raab, W. : In Advances of Cardiology, Vol. 1 : 65: 1956, Basel-New York, S. Karger.

9. Woolley, D.W. et al. : Ann. New York Acad. Sci. 30: $3 ; 551,1959$.

10. Shone, H.H. and Lindner, E. : Arzneimittelforsch. 10: 45, 1960.

11. Weil-Malherbe, H. and Bone: Neurochem. 4: 251, 1959.

12. Well-Malherbe, H.: Pharm. Rev. 11: 278, 1959.

13. Euler, U.S. v. and Floding, I.: Acta Physiol. Scand. 33 : Suppl. 118: 45, 1955.

14. Euler, U.S. v. and Lishajko, F.: Acta Physiol. Scand. 51 : 348, 1961.

15. Miyahara, M. : Jap. Circulat. J. 26: 1, 1962.

16. Klouda, M.A.: Proc. Soc. Exp. Med. 112: 728, 1963.

17. Raab, W. and Gigce, W.: Arch. Exp. Path. Pharamakol. Naunynschwiedeberg's 219: 248 , 1962.

18. Russell. R., Crafoord, J., and Harris, S.: Am. J. Physiol. 200 : 995, 1961.

19. Euler, U.S.v. : Circulat. Res. 4 : 647, 1956.

20. Trendelenburg, U. : J. Pharm. Exp. Therap. 134: 8, 1961.

21. Chidsey, C.A. Kahler, R.L., Kelminson, L.L., and Braunwald, E. : Circulat. Res. 12 : $220,1963$.

22. Kopin, I. J. and Gordon, E.K. : J. Pharm. Exp. Therap. 138: 351, 1962.

23. Pletscher, A.: Experientia 14: 73, 1958.

24. Raab, W.: Am. J. Cardiol. 9: 576, 1962.

25. Cameron, P.D.: Johns Hopkins Hospital Reports $16: 549,1911$.

26. Weiss, S. and Ellis, L.B. : Arch. Int. Med. 52 : 105, 1953.

27. Wayne, E.J. and Laplace, L.B.: Clin. Sc. 1 : 103, 1933.

28. Katz, L.N., Lindner, E., Weinstein, W., Abramson. E.I., and Jochim, K.: Arch. internat. pharmacodyn. therap. 59 : 399, 1938.

29. Essex, H.E., Wegria, K.G.E., Herrick, J.F., and Mann, F.C. : Am. Heart J. 19 : 5.54, 1940.

30. Foltz, E.L., Rubin, A., Steiger, W.A., and Gzes, P.C.: Circulation $2: 215,1950$.

31. Wigria, R., Nickerson, J.L., Case, R.B., and Holland, J.F.: Am. J. Med. 10: 414, 1951.

32. Muller, O. and Rorvik, K. : Brit. Heart J. 20 : 302, 1958.

33. Sarnoff, S.J., Case, R.B., and Macruz, R. : Circulat. Res. 6 : 522, 1958.

34. Brunton, T.L.: New York, The Macmillan Go. 1897.

35. Echenfoff, J.E., Hafkenschiel, J.H., and Landmesser, C.M.: Am. J. Physiol. 148 : 582, 1947.

36. Eldridge, F.L., Hultgren, H.N., Stewart. P., and Proctor, D: Stanford M. Bull. 13: 273, 1955.

37. Brachfeld, N., Boger, J., and Gorlin, R.: Girculation 19:697, 1959.

38. Gorlin, R., Brachfelt, N., MacLeod, C., and Bopp, P.: Circulation $19: 705,1959$.

39. Krantz, J.C., Jr., Carr, C.J., and Knepp, M.J. : J. Pharm. Exp. Therap. 102 : 258, 1951.

40. Krantz, J.C., Jr., Carr, C.J., and Btjant, H.: J. Pharm. Exp. Therap. 102 : 161, 1951.

41. Honig, G.R., Tenney, S.M., and Gabel, P.V.: Am J. Med. 29 : 910, 1960.

42. Hunter, F.E., Jr., Kahana, S., and Ford, L. : Fed. Proc. 12: 221, 1953.

43. Unghavary, V.L., Hovanyi, M., and Farkas, F.: Zeitschrift für Kreislaufforschung 51 : 1096 , 1963.

44. Goldberg, N.D. and Shidemam, F.E.: Fed. Proc. 20: 128, 1961.

45. Rabb, W. and Lepeschkin, E.: Circulation 1: 733, 1950. 